\title{
OPEN A randomized clinical trial on the effect of a lidocaine patch on shoulder pain relief in laparoscopic cholecystectomy
}

\author{
Ha Yeon Kim ${ }^{1,2}$, Jong Bum Choi ${ }^{1}{ }^{2}$, Sang Kee Min ${ }^{1}$, Min Ying Chang ${ }^{1}$, Gang Mee Lim $^{1}$ \& \\ Ji Eun Kim ${ }^{1 凶}$
}

The incidence of laparoscopy-related shoulder pain reaches $90 \%$ in women. We evaluated the effect of lidocaine patch $5 \%$ on the shoulder pain after laparoscopic cholecystectomy (LC) in female patients. Total 63 female patients were randomly allocated to patch group $(n=31)$ and control group $(n=32)$. Patch group received lidocaine patch $5 \%$ and dressing retention tape on both shoulder, and control group received only dressing retention tape. Abdominal and shoulder pains were evaluated with rating on numeric rating scale ( $0=$ no pain and $10=$ the worst pain) at baseline and at $30 \mathrm{~min}, 6 \mathrm{~h}, 24 \mathrm{~h}$, and $48 \mathrm{~h}$ after surgery. There were no significant differences in patient characteristics and operation details. The overall incidence of shoulder pain was significantly lower in patch group than in control group ( $42 \%$ vs. $78 \%, P=0.005)$. The severity of shoulder pain also was significantly reduced in patch group compared to control group at $24 \mathrm{~h}$ and $48 \mathrm{~h}$ after surgery $(P=0.01$ and $P=0.015$, respectively). Complications related to lidocaine patch were not found except nausea. Lidocaine patch $5 \%$ reduced the incidence and severity of postoperative shoulder pain in female patients undergoing LC without complications.

Laparoscopic cholecystectomy (LC) has become a standard treatment for gall bladder disease because of advantages such as smaller incision, shorter hospital stays and faster recovery compared with open cholecystectomy ${ }^{1}$. Although LC is considered as a less painful procedure, patients may experience shoulder pain after undergoing LC. Shoulder pain after surgery occurs rarely in open surgery, but its incidence rises to $30-60 \%$ in general laparoscopic surgery, reaching $90 \%$ in women ${ }^{2-4}$. Some patients unexpectedly may experience severe pain in laparoscopic surgery than in aggressive, major surgeries ${ }^{4,5}$. However, laparoscopy-related shoulder pain is poorly responsive to analgesics ${ }^{4}$. Therefore, the efforts to prevent the laparoscopy-related shoulder pain are essential.

Although the mechanism has not been fully clarified, laparoscopy-related shoulder pain is generally considered to develop due to diaphragmatic irritations from direct injury, stretching, or $\mathrm{CO}_{2}$ gas ${ }^{2,3,6}$. Clinically, diaphragmatic irritation manifests as referred pain in the shoulder arising from the phrenic nerve ${ }^{4,7}$. Interventions to reduce shoulder pain after LC aim to minimize diaphragmatic irritation through low-pressure pneumoperitoneum ${ }^{8}$, intraperitoneal instillation of analgesics ${ }^{9}$, drain suction ${ }^{10}$, active gas aspiration ${ }^{11}$ or phrenic nerve block ${ }^{12}$. However, local anesthesia applied to the area of referred pain, and not initial area, has also been shown to be effective in reducing referred pain in the tibialis muscle ${ }^{13}$; further, trigger point injection or a eutectic mixture of local anesthetics (EMLA) cream applied to the shoulders, not the diaphragm, significantly reduced shoulder pain after laparoscopic hysterectomy ${ }^{14}$.

Lidocaine patch $5 \%$ is a topical analgesic that interrupts pain signals in peripheral nociceptors with minimal systemic absorption and few adverse effects ${ }^{15}$. In a randomized controlled study of myofascial pain syndrome, lidocaine patch $5 \%$ decreased the symptoms of pain and the sensation of the skin as effectively as trigger point injection ${ }^{16}$. We hypothesized that application of lidocaine patch $5 \%$ to the shoulder could also reduce the severity of shoulder pain after LC.

The aim of this study was to evaluate the analgesic effect of lidocaine patch $5 \%$ on shoulder pain after LC in female patients.

\footnotetext{
${ }^{1}$ Department of Anesthesiology and Pain Medicine, Ajou University School of Medicine, 164, World cup-ro, Yeongtong-gu, Suwon, Republic of Korea. ${ }^{2}$ These authors contributed equally: Ha Yeon Kim and Jong Bum Choi. 更mail: beye98@aumc.ac.kr
} 


\section{Methods}

This randomized, double-blinded, prospective, parallel-group study was conducted with patients undergoing LC at the Ajou University Health System between February 2017 and September 2017. The Ajou Hospital Institutional Review Board affiliated to Ajou University School of Medicine (protocol number: AJIRB-MEDCT4-16-076) approved the study protocol (ClinicalTrial.gov, NCT02827136, 11/07/2016). This study was conducted in proportion to relevant guidelines and regulations. After obtaining written informed consent from all participants, female patients with American Society of Anesthesiologists (ASA) physical status I, II or III aged 19-85 years, were included. LC included both elective and emergence surgeries performed in the day time (8:00-17:00). Exclusion criteria were as follows: histories of trauma, infection, surgery, or chronic pain involving the shoulders, hypersensitivity to local anesthetics, chronic abuse of opioids, impaired liver or renal dysfunction, or denial to participate in this study.

Interventions. Participants $(n=64)$ were randomized to one of two groups by randomization generator (http://www.random.org) at 1:1 ratio by J.E.K.: the patch group $(\mathrm{n}=32)$ and the control group $(\mathrm{n}=32)$. Assigned group was concealed in a sealed, opaque envelope. Immediately before anesthesia induction, the envelope was opened by an independent investigator who performed all interventions but was not participated in outcome assessment. The anesthesia provider, patients, and preoperative and postoperative outcome assessors did not know the assigned group throughout the study period.

None of the patients received premedication. On arrival to the operating room, basic monitoring including pulse oximetry, electrocardiography, and non-invasive blood pressure measurement was performed. Before anesthesia induction, lidocaine patches $(10 \times 14 \mathrm{~cm}$; Lidotop, Teikoku Seiyaku Co., Kagawa, Japan $)$ were applied to both shoulders of patients in the patch group; then, the lidocaine patches were covered with dressing retention tape $(12 \times 15 \mathrm{~cm}$; Hypafix, BSN Medical GmbH, Hamburg, Germany). In the control group, only dressing retention tape $(12 \times 15 \mathrm{~cm}$; Hypafix $)$ was applied, also to both shoulders. The patients' shoulders were covered with clothes; thus, the outcome assessors could not see it. For anesthesia induction, intravenous (IV) propofol $2 \mathrm{mg} / \mathrm{kg}$ and remifentanil $0.3 \mu \mathrm{g} / \mathrm{kg}$ were started and rocuronium $0.8 \mathrm{mg} / \mathrm{kg}$ was followed. After endotracheal intubation, mechanical ventilation was initiated. For maintenance of anesthesia, remifentanil was infused at a rate of $0.05-0.10 \mu \mathrm{g} / \mathrm{kg} / \mathrm{min}$, and sevoflurane $2-2.5 \%$ was used within a range of bispectral index score $40-60$. In case of mean arterial pressure (MAP) $<60 \mathrm{mmHg}$ or heart rate $(\mathrm{HR})<40$ beats/min, IV ephedrine $4 \mathrm{mg}$ or atropine $0.5 \mathrm{mg}$ was administered, respectively. Approximately $10 \mathrm{~min}$ prior to the end of surgery, IV propacetamol $1 \mathrm{~g}$ was administered for postoperative analgesia. At the end of surgery, sevoflurane were discontinued, and the fresh gas flow was increased to $5 \mathrm{~L} / \mathrm{min}$. To reverse residual neuromuscular blockade, IV neostigmine $50 \mu \mathrm{g} / \mathrm{kg}$ plus glycopyrrolate $10 \mu \mathrm{g} / \mathrm{kg}$ were injected after confirming the train-of-four count $>2$ using a nerve stimulator. After confirming adequate tidal volume, patients were extubated with maintaining the remifentanil infusion of $0.05 \mu \mathrm{g} / \mathrm{kg} / \mathrm{min}$ to prevent the emergence cough. Then, the patients were transferred to a post-anesthesia care unit (PACU).

All procedures were carried out by two skilled surgeons with same method. LC were performed through three abdominal ports (10-mm infraumbilical camera, 5-mm subxipoid, and 5-mm right lateral subcostal ports). $\mathrm{CO}_{2}$ gas was inflated through infraumbilical Veress needle. Abdominal insufflation pressure was set at $12 \mathrm{mmHg}$. Drain was not inserted, and local anesthetics were not injected at peritoneum or port site.

Data collection. The primary outcome of this study was the severity of shoulder pain after surgery. Preoperative variables included demographics, ASA physical status, and diagnosis. Intraoperative variables included anesthesia time, operation time, and amounts of crystalloid and bleeding. Hemodynamic data such as HR and MAP were collected at five time points: at baseline, at pneumoperitoneum, at $20 \mathrm{~min}$ and $30 \mathrm{~min}$ after pneumoperitoneum, and at the end of surgery. Pain included the abdominal pain, and overall, right, and left shoulder pains. The incidence of shoulder pain was evaluated based on the overall value of shoulder pain and defined as the number of patients who had a pain score that was higher than the value at baseline. "> abdominal pain" was defined as the number of patients who had worse shoulder pain compared with abdominal pain during the $48 \mathrm{~h}$ following surgery. "Alleviated pain" was defined as the number of patients who had less shoulder pain compared to value at baseline. The severity of pain was quantified on a numeric rating scale (NRS) ranging from 0 to 10 $(0=$ no pain and $10=$ the worst pain) at five time points: at baseline, and at $30 \mathrm{~min}, 6 \mathrm{~h}, 24 \mathrm{~h}$, and $48 \mathrm{~h}$ after surgery. The pain score at $48 \mathrm{~h}$ after surgery was investigated by phone call with the patient. Nausea was graded into four $(1=$ none, $2=$ mild, $3=$ moderate, and $4=$ severe). IV ramosetron $0.3 \mathrm{mg}$ was administered to with vomiting or nausea grade $\geq 3$ or 4 . The lidocaine patches and/or dressing retention tape were removed by the ward's attending nurse at $12 \mathrm{~h}$ following surgery. Complications related to lidocaine patch $5 \%$ (skin erythema, pruritus, blisters, contact hypersensitivity, nausea, headache, and arrhythmia) were evaluated by the ward's attending nurse at ward until discharge from the hospital.

Postoperative pain treatment. On arrival to the PACU, IV fentanyl $1 \mu \mathrm{g} / \mathrm{kg}$ was administered as a rescue analgesic in patients reporting an NRS $\geq 5$. At the ward, IV ketorolac $30 \mathrm{mg}$ was administered at $8 \mathrm{~h}$ intervals on the day of surgery. In addition, IV nefopam $20 \mathrm{mg}$ was administered as a rescue analgesic in patients reporting an NRS $\geq 5$. At the postoperative day 1 , the patient discharged with prescription drug, which was consist of oral acetaminophen/tramadol 325/37.5 $\mathrm{mg}$ at three times a day.

Statistical analysis. To calculate the sample size, we focused on the severity of shoulder pain after surgery. In a previous study, the pain score of shoulder pain after LC was $4.43 \pm 1.4^{17}$. Considering that a mean difference 


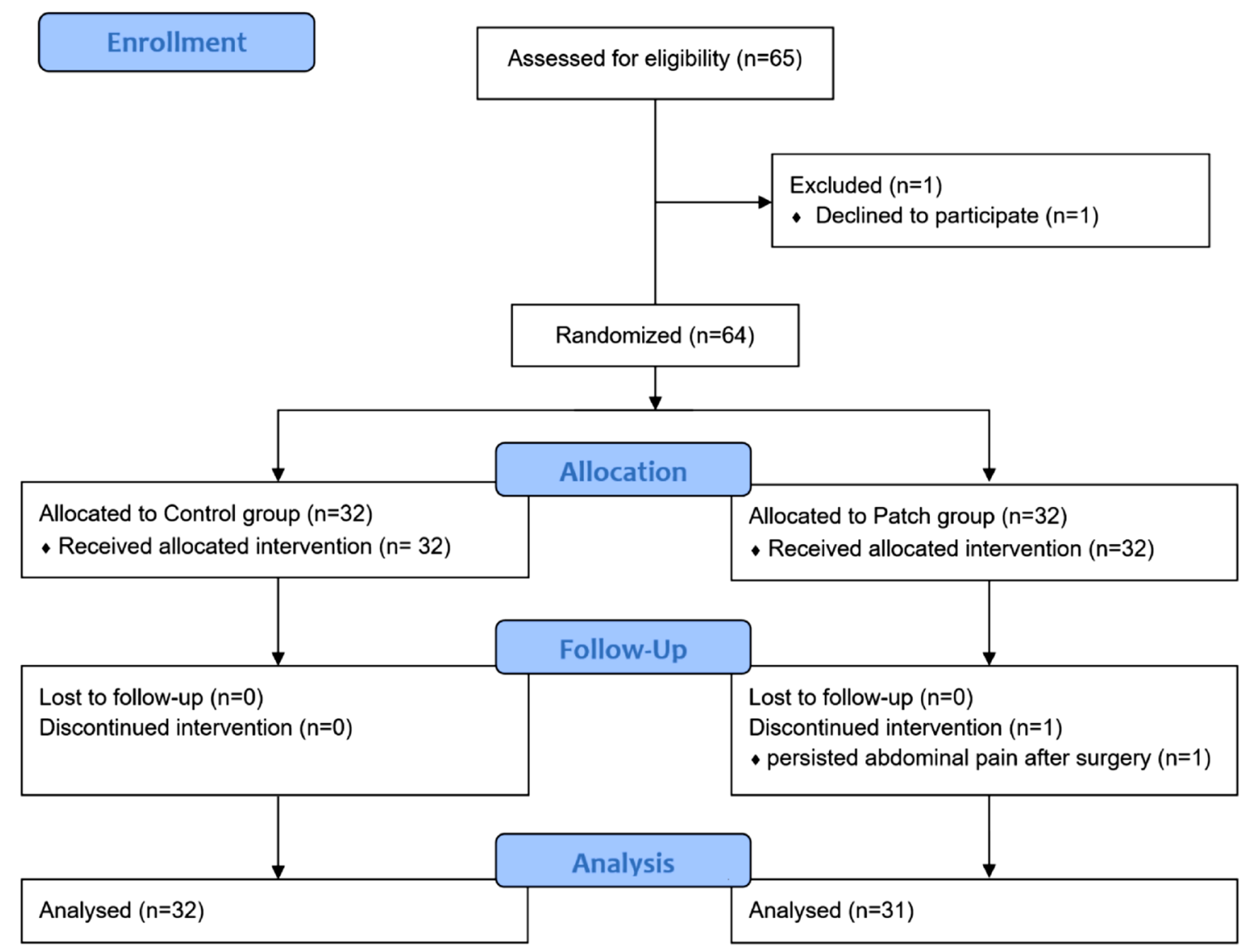

Figure 1. Flow diagram.

of 1.2 in pain score was significant ${ }^{18}, 29$ participants were required in each group for a type I error of $5 \%$ and a power of $90 \%$. Considering a 10\% dropout rate, a total of 64 patients (32 per group) were required.

Data are shown as mean \pm standard deviation (or standard error), median (interquartile range), or number of patients (proportion). Normality of distribution was assessed with the Kolmogorov-Smirnov test. Parametric and nonparametric data were analyzed using Student's t-test and the Mann-Whitney test, respectively. Categorical data were analyzed using the chi-square test or Fisher's exact test. Repeated measured data were analyzed using the linear mixed model. When the interaction was statistically significant, the adjusted P value was obtained with Bonferroni correction. $\mathrm{P}<0.05$ was considered statistically significant. SPSS for Windows (version 25.0, SPSS Inc., Chicago, IL, USA) was used for statistical analyses.

\section{Results}

Of the 64 patients included in this study between February 2017 and September 2017, one patient in the patch group dropped out due to persisting intolerable abdominal pain; finally, the data of 63 patients were analyzed (Fig. 1). There were no significant differences in the patient characteristics and operation details between the two groups (Table 1). Intraoperative HR and MAP were comparable throughout the study period (Fig. 2).

The overall incidence of shoulder pain was significantly lower in the patch group than in the control group ( $42 \%$ vs. $78 \%, P=0.005$, Table 2 ). The incidence of shoulder pain at each time point except the baseline was also lower in the patch group. The number of patients showing more severe shoulder pain than abdominal pain was higher in the control group $(\mathrm{P}=0.041)$, and the number of patients showing less shoulder pain compared to baseline was higher in the patch group $(\mathrm{P}=0.024)$.

Abdominal pain showed a peak of severity at $30 \mathrm{~min}$ after surgery and gradually decreased thereafter in both groups $\left(\mathrm{P}_{\text {group }}\right.$ time $=0.868$; Fig. $\left.3 \mathrm{a}\right)$. Overall shoulder pain showed a peak of severity at $24 \mathrm{~h}$ after surgery in both groups (Fig. 3b). In addition, overall shoulder pain tended to be significantly different between the two groups over time $\left(\mathrm{P}_{\text {time }}<0.001\right)$ and was significantly lower in the patch group than in the control group at $24 \mathrm{~h}$ and $48 \mathrm{~h}$ after surgery [mean value (SE); $1.3(0.4)$ vs $3.3(0.4), \mathrm{P}_{\text {adjusted }}=0.01$ and $0.9(0.4)$ vs $2.5(0.4), \mathrm{P}_{\text {adjusted }}=0.015$ at $24 \mathrm{~h}$ and $48 \mathrm{~h}$, respectively]. Right shoulder pain was lower in the patch group at $24 \mathrm{~h}$ after surgery $\left(\mathrm{P}_{\text {adjusted }}=0.01\right.$; Fig. 3c), and left shoulder pain was lower in the patch group at $24 \mathrm{~h}$ and $48 \mathrm{~h}$ after surgery $\left(\mathrm{P}_{\text {adjusted }}=0.005\right.$ for both; Fig. 3d) compared with control group.

Right shoulder pain did not differ from left shoulder pain in either group $\left(\mathrm{P}_{\text {group*time }}=0.613\right.$ and $\mathrm{P}_{\text {group }}$ time $=0.449$ in the control group and patch group, respectively; Fig. 4). 


\begin{tabular}{|l|l|l|r|}
\hline & Control group (n=32) & Patch group (n=31) & P value \\
\hline Age $($ years) & $52(42-63)$ & $47(40-61)$ & 0.527 \\
\hline Height $(\mathrm{cm})$ & $158(153-163)$ & $159(155-161)$ & 0.581 \\
\hline Weight $(\mathrm{kg})$ & $61.3 \pm 10.8$ & $58.1 \pm 9.8$ & 0.229 \\
\hline BMI $\left(\mathrm{kg} / \mathrm{m}^{2}\right)$ & $24(22-27)$ & $23(21-25)$ & 0.284 \\
\hline ASA physical status $(1 / 2 / 3)$ & $18 / 13 / 1$ & $19 / 12 / 0$ & $>0.999$ \\
\hline Diagnosis & \multicolumn{3}{|l|}{} \\
\hline Adenomyomatosis or polyps & $9(28 \%)$ & $12(39 \%)$ & 0.743 \\
\hline Cholecystitis & \multicolumn{5}{|l|}{} & \\
\hline Mild & $12(38 \%)$ & $10(32 \%)$ & \\
\hline Moderate & $2(6 \%)$ & $3(10 \%)$ & \\
\hline Severe & $9(28 \%)$ & $6(19 \%)$ & 0.916 \\
\hline Crystalloid $(\mathrm{mL})$ & $300(275-400)$ & $300(275-400)$ & 0.938 \\
\hline Bleeding $(\mathrm{mL})$ & $10(10-20)$ & $15(5-20)$ & 0.055 \\
\hline Total dose of remifentanil $(\mu \mathrm{g})$ & $400(320-600)$ & $350(280-400)$ & 0.229 \\
\hline Operation time $(\mathrm{min})$ & $50(40-65)$ & $50(35-57.5)$ & 0.348 \\
\hline Anesthesia time $(\mathrm{min})$ & $85(70-97.5)$ & $80(65-90)$ & \\
\hline
\end{tabular}

Table 1. Patient's characteristics and operation details. Values are presented as mean \pm standard deviation, median (interquartile range) or number (proportion). BMI body mass index, ASA American Society of Anesthesiologists.

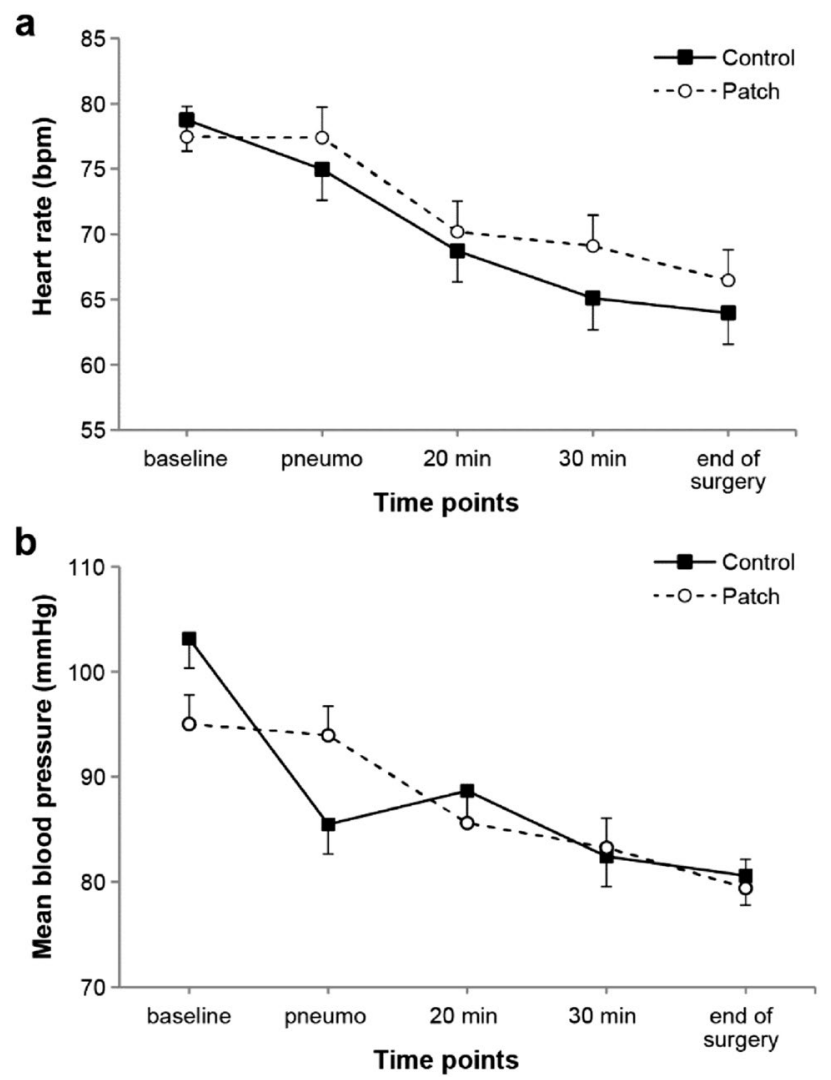

Figure 2. Changes of heart rate (a) and mean blood pressure during surgery (b). Values were expressed as mean \pm standard error. Baseline before anesthesia induction, pneumo at pneumoperitoneum, $20 \mathrm{~min} 20 \mathrm{~min}$ after pneumoperitoneum, $30 \mathrm{~min} 30 \mathrm{~min}$ after pneumoperitoneum, end of surgery $10 \mathrm{~min}$ before the end of surgery. 


\begin{tabular}{|c|c|c|c|}
\hline & Control group $(n=32)$ & Patch group $(n=31)$ & P value \\
\hline \multicolumn{4}{|l|}{ Incidence $^{a}$} \\
\hline Overall & $25(78 \%)$ & $13(42 \%)$ & 0.005 \\
\hline Baseline & $4(13 \%)$ & $7(23 \%)$ & 0.337 \\
\hline 30 min after surgery & $6(19 \%)$ & 0 & 0.024 \\
\hline $6 \mathrm{~h}$ after surgery & $15(47 \%)$ & $6(19 \%)$ & 0.032 \\
\hline $24 \mathrm{~h}$ after surgery & $22(69 \%)$ & $11(35 \%)$ & 0.012 \\
\hline $48 \mathrm{~h}$ after surgery & $20(63 \%)$ & $8(26 \%)$ & 0.005 \\
\hline$>$ Abdominal pain ${ }^{\mathrm{b}}$ & $12(37 \%)$ & $4(13 \%)$ & 0.041 \\
\hline Alleviated pain ${ }^{c}$ & 0 & $5(16 \%)$ & 0.024 \\
\hline
\end{tabular}

Table 2. Incidence of shoulder pain. Values are presented as number (proportion). ${ }^{\text {a }}$ Incidence was defined as the number of patients having higher shoulder pain compared with baseline. ${ }^{\mathrm{b}}$ The number of patients having worse shoulder pain compared with abdominal pain. ${ }^{c}$ The number of patients having less shoulder pain compared with baseline.
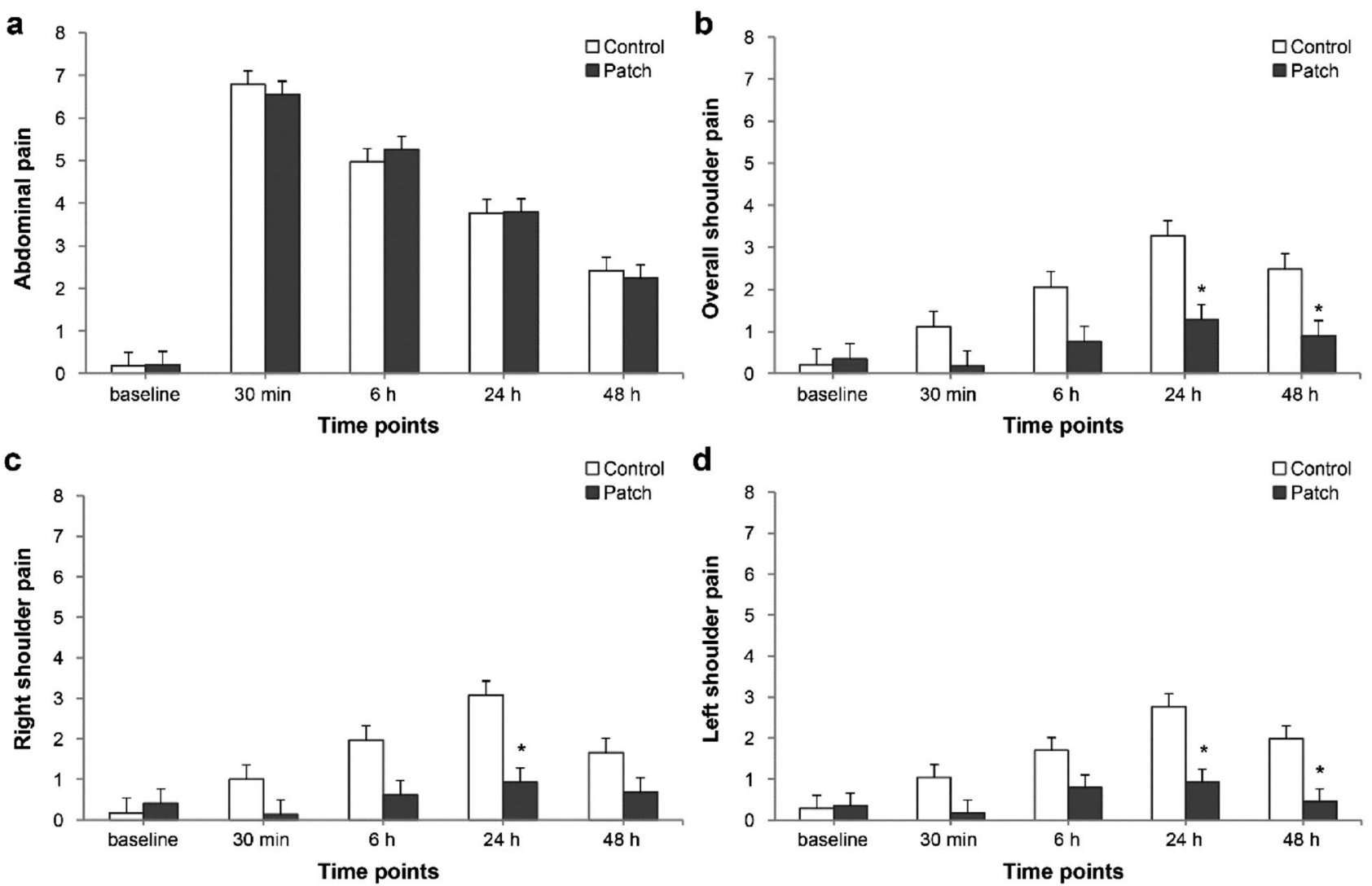

Figure 3. Changes of abdominal pain (a), and overall (b), right (c), and left shoulder pain (d) during the first $48 \mathrm{~h}$ after surgery. Values were expressed as mean \pm standard error. Baseline before anesthesia induction, $30 \mathrm{~min}$ $30 \mathrm{~min}$ after surgery, $6 \mathrm{~h} 6 \mathrm{~h}$ after surgery, $24 \mathrm{~h} 24 \mathrm{~h}$ after surgery, $48 \mathrm{~h} 48 \mathrm{~h}$ after surgery. ${ }^{\star} \mathrm{P}<0.05$ compared with the control group.

The recovery data were comparable between the two groups (Table 3). Nausea developed in 24 patients (12 patients in each group) during PACU or ward stay; no other complications related to the use of lidocaine patch $5 \%$ or dressing retention tape were found.

\section{Discussion}

This study demonstrated the beneficial analgesic effect of lidocaine patch 5\% on decreasing shoulder pain after LC in female patients. The incidence of shoulder pain in the patch group was significantly reduced up to approximately $50 \%$ of that in the control group. The severity of shoulder pain also was significantly reduced in the patch group at $24 \mathrm{~h}$ and $48 \mathrm{~h}$ after surgery. The number of patients showing more severe shoulder pain than abdominal pain was higher in the control group, and the number of patients having less shoulder pain compared to baseline was higher in the patch group. 

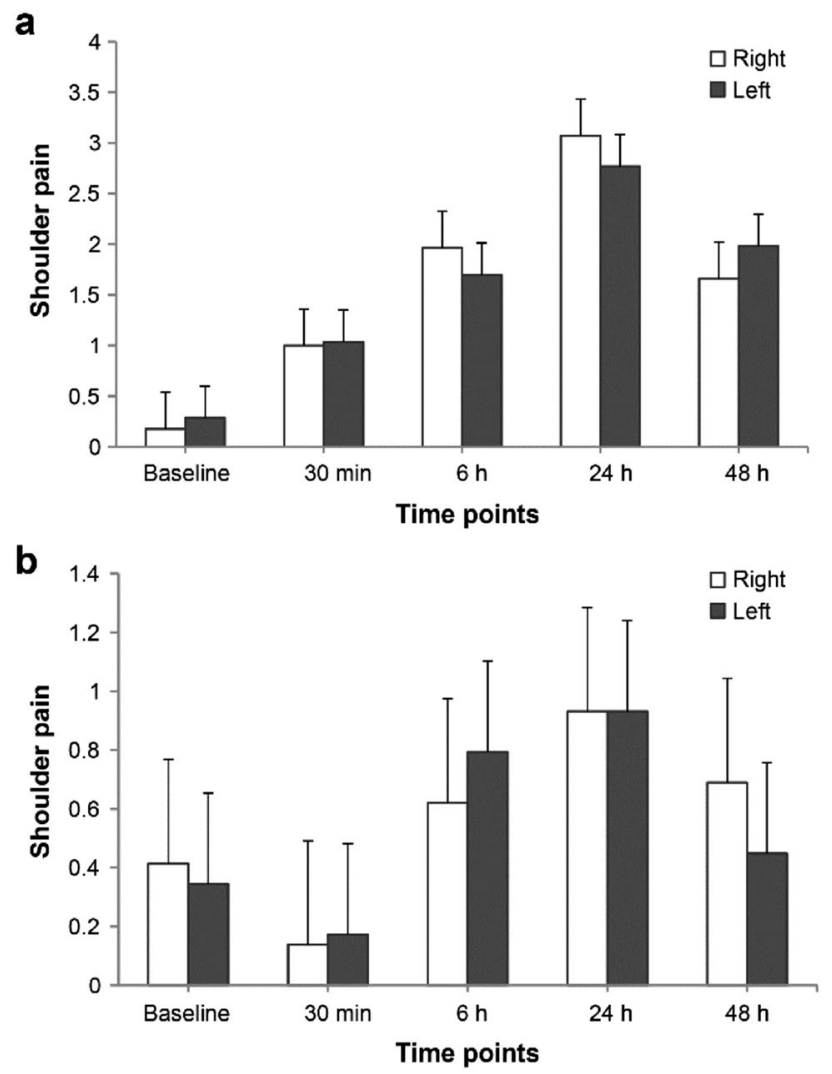

Figure 4. Comparison between right and left shoulder pain in control group (a) and patch group (b). Values were expressed as mean \pm standard error. Baseline before anesthesia induction, $30 \mathrm{~min} 30 \mathrm{~min}$ after surgery, $6 \mathrm{~h}$ $6 \mathrm{~h}$ after surgery, $24 h 24 \mathrm{~h}$ after surgery, $48 \mathrm{~h} 48 \mathrm{~h}$ after surgery.

\begin{tabular}{|l|l|l|r|}
\hline \multicolumn{2}{|l|}{ Control group (n=32) } & Patch group (n=31) & P value \\
\hline In PACU & $26 / 0 / 1 / 5$ & $21 / 3 / 2 / 5$ & 0.323 \\
\hline Nausea & $2(6 \%)$ & $2(7 \%)$ & $>0.999$ \\
\hline Vomiting & $7(22 \%)$ & $8(26 \%)$ & 0.714 \\
\hline Patient requesting antiemetics & $25(78 \%)$ & $25(81 \%)$ & 0.805 \\
\hline Patient requesting analgesic & $57(11-68)$ & $54(46-67)$ & 0.803 \\
\hline Rescue fentanyl dose $(\mu \mathrm{g})$ & $40(30-50)$ & $40(40-50)$ & 0.190 \\
\hline Duration of PACU stay (min) & & & \\
\hline At ward & & $3(10 \%)$ & 0.708 \\
\hline Complications & $5(16 \%)$ & $1(3 \%)$ & $>0.999$ \\
\hline Fever & $2(6 \%)$ & $4(13 \%)$ & 0.222 \\
\hline Urinary retention & $8(25 \%)$ & $2(7 \%)$ & $>0.999$ \\
\hline Nausea & $3(9 \%)$ & $1(3 \%)$ & 0.492 \\
\hline Vomiting & 0 & $3(10 \%)$ & 0.672 \\
\hline Hypotension & $2(6 \%)$ & $19(61 \%)$ & 0.513 \\
\hline Patient requesting antiemetics & $17(53 \%)$ & $1(1-1)$ & 0.468 \\
\hline Patient requesting analgesic & $1(1-2)$ & & \\
\hline Hospital stay after surgery $($ day $)$ & & & \\
\hline
\end{tabular}

Table 3. Recovery profiles. Values are presented as median (interquartile range) or number (\%). PACU postanesthesia care unit. 
Although still unclear, the most probable mechanism of laparoscopy-related shoulder pain is the excitation of the phrenic nerve due to diaphragmatic or peritoneal irritation ${ }^{2,3,6,19}$. The phrenic nerve originates from the anterior branch of cervical spinal nerve roots $\mathrm{C} 3-\mathrm{C} 5$ and provides sensory innervation to the mediastinal pleura, pericardium, and peritoneal surfaces of the diaphragm ${ }^{7,12}$. The main nerve $\mathrm{C} 4$ also provides cutaneous innervation to the shoulder. Regarding the misinterpretation of the origin of input from the referred pain area ${ }^{20,21}$, diaphragmatic irritation during laparoscopy can provoke referred shoulder pain. Based on this "misinterpretation theory," numerous strategies have been developed to reduce laparoscopy-related shoulder pain by minimizing diaphragmatic irritation. These interventions are sometimes effective, but the results are conflicting and there is no consensus on preventive measures.

A "pre-local hyper-excitability theory" has been proposed, in which stimuli in the initial area cause the hyperexcitation of the connective nerve between the referred area and initial area, consequently inducing the increased sensitivity of the referred area ${ }^{22}$. According to this theory, the primary pathogenesis is peripheral sensitization rather than central sensitization. In experimental studies on healthy volunteers, referred pain was partially decreased when the input from the peripheral receptors in the referred area was blunted, though conflicting results have been published ${ }^{20,21}$. For example, an EMLA cream over the referred skin area reduced the intensity of referred pain by $22.7 \%{ }^{23}$, and a complete nerve block in the referred area reduced it by $40 \%{ }^{13}$. In clinical studies on patients undergoing laparoscopic surgery, treatment on the shoulder effectively decreased referred shoulder pain after laparoscopy. For example, pretreatment using a trigger point injection or an EMLA cream on the shoulder significantly reduced the incidence and severity of shoulder pain after laparoscopy ${ }^{14}$. Moreover, transcutaneous electrical nerve stimulation on the shoulder alleviated shoulder pain during laparoscopy ${ }^{24}$. Based on these studies, we hypothesized that the application of a lidocaine patch to the shoulder could also reduce referred shoulder pain after laparoscopic surgery. In the present study, lidocaine patch $5 \%$ was applied to the referred pain area (the shoulder); consequently, the incidence and severity of shoulder pain after LC were reduced significantly.

Lidocaine patch $5 \%$ is a skin patch approved for the treatment of post-herpetic neuralgia. It is also used for localized and painful conditions such as vascular access, pain caused by trauma fracture, wound pain after surgery, and arthritis ${ }^{18,25}$. Each patch contains $700 \mathrm{mg}$ of lidocaine in aqueous base, but only $2-3 \%$ of the dose is absorbed; the peak plasma level is $0.13 \mu \mathrm{g} / \mathrm{mL}$ (toxic level, $5 \mu \mathrm{g} / \mathrm{mL}$ ), thus showing minimal adverse effects ${ }^{26}$. In a previous study, application of an EMLA cream on the shoulders reduced laparoscopy-related shoulder pain to an NRS score of $<1^{14}$, which was more effective than the lidocaine patch $5 \%$ used in present study (mean NRS scores of 1.3 and 0.9 at $24 \mathrm{~h}$ and $48 \mathrm{~h}$ after surgery, respectively). One of differences between the EMLA cream and the lidocaine patch is that EMLA produces local anesthesia by blocking large sensory fibers ${ }^{15}$ and the lidocaine patch exerts an analgesic effect by blocking the small sensory fibers without causing local anesthesia. Thus, the skin under the lidocaine patch has a normal sensation ${ }^{15}$. Despite the low analgesia potency, the lidocaine patch might be better for surgical patients than the EMLA cream due to the lack of numbness and occlusive dressing.

The peak shoulder pain score in this study was 1.3 at $24 \mathrm{~h}$ after surgery in the patch group. This was lower than the scores ranging from 1.9 to 4.2 in studies focusing on lessening diaphragmatic irritation during $\mathrm{LC}^{12,17,27}$. In addition, the present study only included female patients who have a lower pain threshold than male ${ }^{28}$. This is interesting finding that shoulder intervention showed more effective analgesia than diaphragmatic intervention during LC, because referred pain has been known to be mainly associated with central components (initial area) and not with peripheral components (referred area).

In the present study, shoulder pain after LC was reduced until $48 \mathrm{~h}$ after surgery despite the application of the lidocaine patch during the first $12 \mathrm{~h}$. Lidocaine patch $5 \%$ has a half-life of $6-8 \mathrm{~h}^{15}$. In patients with myofascial pain syndrome, the effect of lidocaine patch $5 \%$ applied to three focal sites throughout the body for 4 days was superior to that of a placebo patch until day 9 after the beginning of treatment ${ }^{16}$. Similarly, in an area limited to the upper trapezius, a lidocaine patch applied for 7 days also relieved pain more effectively than a placebo patch for a period of 2 weeks ${ }^{29}$. There are two possible explanations for the long analgesic period of the lidocaine patch. First, after long-term application, lidocaine patch $5 \%$ decreases epidermal nerve fiber density without affecting pressure pain and threshold for heat- and cold-induced pain in the skin of healthy volunteers ${ }^{30}$. Second, central sensitization might play a role in persistent complaints in patients with shoulder pain ${ }^{31}$, although being poorly investigated. In the present study, the antinociceptive effect of lidocaine patch $5 \%$ that was initiated before the pneumoperitoneum might inhibit the central sensitization of the shoulder to some degree.

Right and left shoulder pain did not differ in the patch and control groups in present study. Shoulder pain after LC is generally more frequent in the right side ${ }^{2}$. During laparoscopic hysterectomy, right shoulder pain was more severe than left shoulder pain ${ }^{32}$. In contrast, Schoeffler et al. reported that more severe shoulder tip pain is noted in the left side in reference with protection of the right side of the diaphragm through the liver ${ }^{33}$. Further research is required to evaluate which side is more affected.

This study has several limitations. First, the sample size might be small when considering the simple intervention. Further studies are needed to verify our findings in a larger sample size. Second, shoulder pain scores were not evaluated by dividing separately during rest and movement. Third, when patients requested rescue analgesics, the main site of complaint was not evaluated. Fourth, more-than-mild pain (NRS $\geq 4$ ) has considerable clinical significance. Regretfully, the number of patients with shoulder pain of NRS $\geq 4$ was similar in this study (10 [31\%] vs. $4[13 \%]$ in the control vs. patch groups, $\mathrm{P}=0.08$ ). Fifth, at the time of patch removal by a nurse, the patient might have not remained blinded. Shame patches may be needed for complete blinding. Sixth, longer follow-up time of patients would be needed, because post-laparoscopic pneumoperitoneum was detected on upright chest radiographs in patients undergoing LC within the first week after surgery ${ }^{34}$.

In conclusion, lidocaine patch $5 \%$ reduced the incidence and severity of postoperative shoulder pain in female patients undergoing LC. Application of lidocaine patch 5\% on the shoulder can be a simple, non-invasive, and effective analgesic method without adverse effects. 


\section{Data availability}

The datasets generated during and/or analyzed during the current study are available from the corresponding author on reasonable request.

Received: 22 May 2020; Accepted: 18 December 2020

Published online: 13 January 2021

\section{References}

1. Keus, F., Gooszen, H. G. \& van Laarhoven, C. J. Open, small-incision, or laparoscopic cholecystectomy for patients with symptomatic cholecystolithiasis. An overview of Cochrane Hepato-Biliary Group reviews. Cochrane Datab. Syst. Rev. 1, 1-23 (2010).

2. Bisgaard, T., Kehlet, H. \& Rosenberg, J. Pain and convalescence after laparoscopic cholecystectomy. Eur. J. Surg. Acta Chirurgica $167,84-96(2001)$.

3. Kandil, T. S. \& El Hefnawy, E. Shoulder pain following laparoscopic cholecystectomy: Factors affecting the incidence and severity. J. Laparoendosc. Adv. Surg. Tech. Part A 20, 677-682 (2010).

4. Lee, D. H., Song, T., Kim, K. H. \& Lee, K. W. Incidence, natural course, and characteristics of postlaparoscopic shoulder pain. Surg. Endosc. 32, 160-165 (2018).

5. Gerbershagen, H. J. et al. Pain intensity on the first day after surgery: A prospective cohort study comparing 179 surgical procedures. Anesthesiology 118, 934-944 (2013).

6. Joris, J., Thiry, E., Paris, P., Weerts, J. \& Lamy, M. Pain after laparoscopic cholecystectomy: Characteristics and effect of intraperitoneal bupivacaine. Anesth. Analg. 81, 379-384 (1995).

7. Morelot-Panzini, C., Le Pimpec-Barthes, F., Menegaux, F., Gonzalez-Bermejo, J. \& Similowski, T. Referred shoulder pain (C4 dermatome) can adversely impact diaphragm pacing with intramuscular electrodes. Eur. Respir. J. 45, 1751-1754 (2015).

8. Bhattacharjee, H. K. et al. Impact of standard-pressure and low-pressure pneumoperitoneum on shoulder pain following laparoscopic cholecystectomy: A randomised controlled trial. Surg. Endosc. 31, 1287-1295 (2017).

9. El-Labban, G. M. et al. Intraincisional vs intraperitoneal infiltration of local anaesthetic for controlling early post-laparoscopic cholecystectomy pain. J. Minimal Access Surg. 7, 173-177 (2011).

10. Hosseinzadeh, F., Nasiri, E. \& Behroozi, T. Investigating the effects of drainage by hemovac drain on shoulder pain after female laparoscopic surgery and comparison with deep breathing technique: a randomized clinical trial study. Surg. Endosc. https://doi. org/10.1007/s00464-00019-07339-z (2020).

11. Atak, I. et al. Active gas aspiration to reduce pain after laparoscopic cholecystectomy. Surg. Laparosc. Endosc. Percutaneous Tech. 21, 98-100 (2011).

12. Yi, M. S. et al. Effect of ultrasound-guided phrenic nerve block on shoulder pain after laparoscopic cholecystectomy-A prospective, randomized controlled trial. Surg. Endosc. 31, 3637-3645 (2017).

13. Laursen, R. J., Graven-Nielsen, T., Jensen, T. S. \& Arendt-Nielsen, L. Referred pain is dependent on sensory input from the periphery: A psychophysical study. Eur. J. Pain (London, England) 1, 261-269 (1997).

14. Kim, J. E., Kim, J. Y., Lee, H. S., Seok, S. \& Kil, H. K. Analgesic effect of trigger point injection and EMLA for shoulder pain in patients undergoing total laparoscopic hysterectomy: A randomized controlled study. Medicine (Baltimore) 98, e14087 (2019).

15. Gammaitoni, A. R., Alvarez, N. A. \& Galer, B. S. Safety and tolerability of the lidocaine patch $5 \%$, a targeted peripheral analgesic: A review of the literature. J. Clin. Pharmacol. 43, 111-117 (2003).

16. Affaitati, G. et al. A randomized, controlled study comparing a lidocaine patch, a placebo patch, and anesthetic injection for treatment of trigger points in patients with myofascial pain syndrome: Evaluation of pain and somatic pain thresholds. Clin. Ther. 31, 705-720 (2009).

17. Yasir, M. et al. Evaluation of post operative shoulder tip pain in low pressure versus standard pressure pneumoperitoneum during laparoscopic cholecystectomy. Surgeon J. R. Coll. Surg. Edinburgh Ireland 10, 71-74 (2012).

18. Khanna, M., Peters, C. \& Singh, J. R. Treating pain with the lidocaine patch $5 \%$ after total knee arthroplasty. PM \& R J. Injury Funct. Rehabilit. 4, 642-646 (2012).

19. Wills, V. L. \& Hunt, D. R. Pain after laparoscopic cholecystectomy. Br. J. Surg. 87, 273-284 (2000).

20. Arendt-Nielsen, L. \& Svensson, P. Referred muscle pain: Basic and clinical findings. Clin. J. Pain 17, 11-19 (2001).

21. Kosek, E. \& Hansson, P. Perceptual integration of intramuscular electrical stimulation in the focal and the referred pain area in healthy humans. Pain 105, 125-131 (2003).

22. Farasyn, A. Referred muscle pain is primarily peripheral in origin: The "barrier-dam" theory. Med. Hypotheses 68, 144-150 (2007).

23. Laursen, R. J., Graven-Nielsen, T., Jensen, T. S. \& Arendt-Nielsen, L. Quantification of local and referred pain in humans induced by intramuscular electrical stimulation. Eur. J. Pain (London, England) 1, 105-113 (1997).

24. Asgari, Z. et al. A comparative study between transcutaneous electrical nerve stimulation and fentanyl to relieve shoulder pain during laparoscopic gynecologic surgery under spinal anesthesia: A randomized clinical trail. Pain Res. Manag. 2018, 9715142 (2018).

25. Cheng, Y. J. Lidocaine skin patch (Lidopat 5\%) is effective in the treatment of traumatic rib fractures: A prospective double-blinded and vehicle-controlled study. Med. Principles Practice Int. J. Kuwait Univ. Health Sci. Centre 25, 36-39 (2016).

26. Mao, J. \& Chen, L. L. Systemic lidocaine for neuropathic pain relief. Pain 87, 7-17 (2000).

27. Sandhu, T. et al. Low-pressure pneumoperitoneum versus standard pneumoperitoneum in laparoscopic cholecystectomy, a prospective randomized clinical trial. Surg. Endosc. 23, 1044-1047 (2009).

28. Frot, M., Feine, J. S. \& Bushnell, M. C. Sex differences in pain perception and anxiety. A psychophysical study with topical capsaicin. Pain 108, 230-236 (2004).

29. Cohen, H. \& Jones, H. W. The reference of cardiac pain to a phantom left arm. Br. Heart J. 5, 67-71 (1943).

30. Wehrfritz, A. et al. Differential effects on sensory functions and measures of epidermal nerve fiber density after application of a lidocaine patch (5\%) on healthy human skin. Eur. J. Pain (London, England) 15, 907-912 (2011).

31. Noten, S. et al. Central pain processing in patients with shoulder pain: A review of the literature. Pain Pract. Off. J. World Inst. Pain 17, 267-280 (2017).

32. Choi, J. B. et al. Pain characteristics after total laparoscopic hysterectomy. Int. J. Med. Sci. 13, 562-568 (2016).

33. Schoeffler, P., Diemunsch, P. \& Fourgeaud, L. Ambulatory celioscopy. Cah. Anesthesiol. 41, 385-391 (1993).

34. Millitz, K. et al. Pneumoperitoneum after laparoscopic cholecystectomy: Frequency and duration as seen on upright chest radiographs. AJR Am. J. Roentgenol. 163, 837-839 (1994).

\section{Acknowledgements}

The authors would like to thank Hye Sun Lee, MS, Biostatistics Collaboration Unit, Yonsei University College of Medicine, Seoul, Republic of Korea. 


\section{Author contributions}

Conception and design: J.E.K.; Provision of study materials or patients: S.K.M.; Collection and assembly of data: H.Y.K. and M.Y.C.; Data analysis and interpretation: J.B.C. and G.M.L.; Manuscript writing: H.Y.K. and J.B.C.; Final approval of manuscript: all authors.

\section{Competing interests}

The authors declare no competing interests.

\section{Additional information}

Correspondence and requests for materials should be addressed to J.E.K.

Reprints and permissions information is available at www.nature.com/reprints.

Publisher's note Springer Nature remains neutral with regard to jurisdictional claims in published maps and institutional affiliations.

(c) (i) Open Access This article is licensed under a Creative Commons Attribution 4.0 International License, which permits use, sharing, adaptation, distribution and reproduction in any medium or format, as long as you give appropriate credit to the original author(s) and the source, provide a link to the Creative Commons licence, and indicate if changes were made. The images or other third party material in this article are included in the article's Creative Commons licence, unless indicated otherwise in a credit line to the material. If material is not included in the article's Creative Commons licence and your intended use is not permitted by statutory regulation or exceeds the permitted use, you will need to obtain permission directly from the copyright holder. To view a copy of this licence, visit http://creativecommons.org/licenses/by/4.0/.

(C) The Author(s) 2021 